\title{
Copper@carbon coaxial nanowires synthesized by hydrothermal carbonization process from electroplating wastewater and their use as an enzyme-free glucose sensor
}

\author{
Yuxin Zhao, ${ }^{a, b}$ Zhaoyang $\mathrm{He}^{\mathrm{c}}$ and Zifeng Yan*a \\ Received (in $X X X, X X X)$ Xth $X X X X X X X X X 20 X X$, Accepted Xth $X X X X X X X X X 20 X X$ \\ DOI: $10.1039 / b 000000 x$
}

In the pursuit of electrocatalysts with great economic and ecological values for non-enzymatic glucose sensors, one-dimensional (1D) copper@carbon (Cu@C) core-shell coaxial nanowires (NWs) have been successfully prepared via a simple continuous flow wet-chemistry approach from electroplating wastewater. The as-obtained products were characterized by X-ray powder diffraction (XRD), scanning electron microscopy (SEM), transmission electron microscopy (TEM), selected area electron diffraction (SAED), energy dispersive X-ray spectroscopy (EDX) and Raman spectroscopy. The electrocatalytic activity of the modified electrodes by $\mathrm{Cu} @ \mathrm{C}$ NWs towards glucose oxidation was investigated by cyclic voltammetry and chronoamperometry. It was found that the as-obtained $\mathrm{Cu} @ \mathrm{C}$ NWs showed good electrochemical properties and could be used as an electrochemical sensor for the detection of glucose molecules. Compared to the other electrodes including bare Nafion/glassy carbon electrode (GCE) and several hot hybrid nanostructures modifed GCE, a substantial decrease in the overvoltage of the glucose oxidation was observed at the $\mathrm{Cu} @ \mathrm{C}$ NWs electrodes with oxidation starting at ca. $0.20 \mathrm{~V} \mathrm{vs.Ag/AgCl} \mathrm{(3}$ $\mathrm{M} \mathrm{KCl})$. At an applied potential of $0.65 \mathrm{~V}, \mathrm{Cu} @ \mathrm{C}$ NWs electrodes produce high and reproducible sensitivity to glucose with $437.8 \mu \mathrm{Acm}^{-2} \mathrm{mM}^{-1}$. Linear responses were obtained with a detection limit of $50 \mathrm{nM}$. More importantly, the proposed electrode also show good stability, high resistance against poisoning by chloride ion and the commonly interfering species. These good analytical performances make $\mathrm{Cu} @ \mathrm{C}$ NWs promising for the future development of enzyme-free glucose sensors.

\section{Introduction}

Development of fast and reliable methods for glucose determination is of considerable essential in many areas such as clinical diagnostics ${ }^{[1]}$, the food industry ${ }^{[2]}$, bio-processing ${ }^{[3]}$ and in the development of renewable, sustainable fuel cells such as microbial fuel cell (MFC) ${ }^{[4-9]}$ The efforts to develop and improve glucose sensors, particularly based on amperometry, have been made over four decades since Clark and Lyons reported the first enzyme elec-trode in 1962. ${ }^{[10]}$ The historical advances in the amperometric glucose sensors can be summarized into four generations. ${ }^{[1]}$ In the first three generations, the glucose sensors based on the strategy of the direct electron transfer from the enzyme to the electrode. However, instability issues originated from the nature of the enzymes that surround enzymatic sensor systems in all fields of science always hinder their development and application. With the aim of finding out a new path instead of facilitating the needs of a fragile and relatively difficult enzyme, the use of non-enzymatic electrodes as glucose sensors potentially promises a fourth generation to analytical glucose oxidation, which is an attractive alternative for the reliable fast determination.

Most enzymeless electrochemical glucose sensors rely on the properties of the electrode materials, on which the glucose is oxidized directly. Actually, many efforts have been concentrated on the choice of electrocatalyst materials such as metals (e.g. $\left.\mathrm{Pt}^{[12-15]}, \mathrm{Au}^{[16,17]}\right)$, metal oxides/semiconductors (e.g. $\mathrm{Ni}(\mathrm{OH})_{2}$, ${ }^{[18]}$ $\mathrm{RuO}_{2}{ }^{[19]}$ ), alloys (e.g. $\mathrm{PtPb},{ }^{[20]} \mathrm{PtRu}^{[21]}$ ), complexes (e.g. cobalt phthalocyanine ${ }^{[22]}$ ) and carbon based (e.g. carbon nanotubes ${ }^{[23,24]}$, boron doped diamond ${ }^{[25]}$ ) for improving the sensing performance of enzymeless sensors. Apart from the latter all the catalysts listed are dependent on a transition metal centre. However, some problems including poisoning by adsorbed intermediates or chloride ions, poor selectivity and low sensitivity still remain. During recent years, considerable attention has been focusing on copper-based materials, especially metallic $\mathrm{Cu}$ and their onedimensional (1D) nanostructures (i.e. $\mathrm{Cu}$ nanorods and nanowires) in order to acquire more economical electrocatalysts for nonenzymatic glucose sensors without the compromise of sensitivity and specificity ${ }^{[26-28]}$. Particularly, copper nanowires ( $\mathrm{Cu}$ NWs) has aroused great interest not only owing to their novel physical and chemical properties such as efficient transport of electrons, optical excitation, good mechanical strength, catalysis stability and enhancing the mass transport over the electrode microenvironment when compared with macroelectrodes, but also because of the potential of assembling complex architectures 
for the systematic fabrication of high performance engineered nanocomposites in a rapid and cost-effective manner. Nevertheless, a few of papers have appeared for fabricating and examining $\mathrm{Cu} \mathrm{NWs}$ in the enzyme-free detection of glucose simultaneously ${ }^{[28]}$, although they demonstrated enhanced sensing performance as a flash in the pan. In fact, the preparation of 1-D oriented nanocopper required either porous templates or multistep complex fabrication procedure at elevated temperature, in addition, pure $\mathrm{Cu}$ NWs do not have good stability for electroanalysis due to their easy oxidization in air and solution. To obtain stable metal NWs and to find new potential properties, inert matter-encapsulated $\mathrm{Cu}$ NWs have attracted extensive interest. Carbon materials such as activated carbon often possesses a large surface area and used as adsorbents for environmental detection due to their good adsorbing abilities. Herein, we report a facile, cost-effective and environmentfriendly method to synthesize $\mathrm{Cu}$ NWs coated with amorphous carbon shells through catching $\mathrm{Cu}^{2+}$ from electroplating wastewater via a continuous flow hydrothermal carbonization process, for which only mild reaction conditions are required. Simultaneous coating and morphology control could be achieved during the synthetic process. Proportionately, we have also improved the synthesis process of $\mathrm{Cu}$ NWs core wrapped by graphite carbon on the basis of previous works ${ }^{[29]}$ for seeking to the impact of these two kinds of carbon shells on sensor performances. Furthermore, the geometry of the electrode is also highly important in light of concentric adsorption theory with adjacent adsorption sites proposed by Pletcher ${ }^{[30]}$. As such, in the fabrication and study of electrocatalysts both electronic and geometric factors must be considered, so as to fully exploit the kinetic enhancements offered by well spaced adsorption sites and increased surface area. In the current study, as-prepared $\mathrm{Cu} @ \mathrm{C}$ amorphous NWs (Cu@C-A NWs), in comparison with $\mathrm{Cu} @ \mathrm{C}$ graphite NWs (Cu@C-G NWs) and $\mathrm{Cu@C-amorphous}$ nanoparticles (NPs) modified multiwall carbon nanotubes (MWCNTs), demonstrated very effective catalytic activity, as well as environmental stability in the electrochemical oxidation of glucose. Successful application of the developed sensor used for the analysis of the glucose demonstrates the applicability of this cable-like hybrid $\mathrm{Cu} @ \mathrm{C}$ nanocomposite in sensitive and selective non-enzymatic glucose detection.

\section{Experimental section}

\subsection{Synthesis of $\mathrm{Cu} @ \mathrm{C}$-amorphous composite nanowires from} electroplating wastewater.

All of the chemical reagents used were of analytical grade except copper source solution. With the development of metallurgical and electronic industries, a large quantity of alkali ammonia etching wastewater containing copper ion were produced, which provides us inherent copper ammonia complex for the formation of $\mathrm{Cu} @ \mathrm{C}$ NWs depends on the aldehyde group within the glucose. Prior to the experiment, these wastewaters must be purified and reclaimed with $\mathrm{pH}$ readjustment before discharging the nanomaterials we wanted, all glass substrates used in preparation process were cleaned successively using detergent, deionized water, acetone, and boiling isopropyl alcohol, each under ultrasonication and then treated with nitrogen purging for $15 \mathrm{~min}$. To prepare feed precursor solutions for a typical synthesizing
$\mathrm{Cu} @ \mathrm{C} N \mathrm{NW}$, purified dilute wastesolution are rich sources of $0.23 \mathrm{M} \mathrm{Cu}^{2+}, 0.31 \mathrm{M} \mathrm{SO}_{4}{ }^{2-}$ and $1.15 \mathrm{M} \mathrm{NH}_{3}{ }^{-}(\mathrm{pH}=10.3)$, and 0.3 $\mathrm{M}$ dextran-40 $\left(\mathrm{H}\left(\mathrm{C}_{6} \mathrm{H}_{10} \mathrm{O}_{5}\right)_{\mathrm{n}} \mathrm{OH}, \mathrm{Mw}=40000\right.$, in water solvent $)$ were, simultaneously, injected dropwise into a round-bottom flask which was magnetically stirred at a rate of $45 \mathrm{~mL} / \mathrm{h}$. Then additional aqueous ammonia was slowly dropped into the solution until the acid estimation apparatus displayed $\mathrm{pH}=11$. Afterwards, cetyltrimethylammonium bromide (CTAB, $0.072 \mathrm{M}$, in water solvent) was dissolved into the mixture followed by vigorous mixing for $0.5 \mathrm{~h}$ until a dark blue emulsion was obtained. Thenceforth, the precursor solution was pre-heated for $3 \mathrm{~min}$ and flowed through a continuous flow reactor (CFR) using a low flow peristaltic pump at a total rate of $1 \mathrm{~mL} / \mathrm{min}$ under refluxing conditions at $150^{\circ} \mathrm{C}$, while reaction waste was separated to prevent their accumulation in the system and, at certain levels, disturbing the stability of $\mathrm{pH}$ environment and proving poor dispersion for the $\mathrm{Cu} @ \mathrm{C}$ NWs. Such that the final concentration of the precursor solution in the reaction column would be persisted unchanged. Here CTAB was used as a surface modified reagent and stabilized reagent to prevent the nanowires from coalescing. $\mathrm{Cu}^{2+}$ ions were reduced to copper metal by the introduction of polydextrose under mild conditions. As the results, much longer Cu@C NWs deposited on the bottom of columnar teflon-lined stainless steel CFR reactor can be obtained. The resulting foxy solution was centrifuged at $4500 \mathrm{rpm}$, and washed with deionized water and ethanol sequentially. The process was repeated several times to remove the excess surfactant, in the end a reddish fluffy solid was obtained.

\subsection{Preparation of the modified electrodes.}

Bare glassy carbon electrode (GCE, 3-mm diameter) were polished before each experiment with emery paper and alumina slurry (CHI Instrument, Shanghai, China) in sequence, then rinsed successively with nitric acid, ethanol, distilled water using bath sonication for $10 \mathrm{~min}$, followed by drying at room temperature. Subsequently, 12 mg Cu@C-A NWs were dispersed in $1.0 \mathrm{ml}$ of ethanol suspension and $5 \mu \mathrm{L}$ drop on the surface of GCE. After drying, $5 \mu \mathrm{L}$ of Nafion (Nf, $0.4 \mathrm{wt} \%$ ) was then cast on the layer of $\mathrm{Cu} @ \mathrm{C}$-A NWs for the purpose of entrapment.

\subsection{Characterization and electrochemical measurements.}

The powder X-ray diffraction (XRD) patterns were obtained from powder samples mounted on glass slides in a PANalytical D/max-IIIA XRD instrument operating with $\mathrm{Cu} \mathrm{K \alpha}$ radiation $(\lambda=1.5406 \mathrm{~nm})$. The morphology and elemental composition of the prepared $\mathrm{Cu} @ \mathrm{C}$ NWs were characterized by scanning electron microscopy (SEM, Netherlands FEI.Co Sirion 200) and energy dispersive X-ray spectroscopy (EDX), respectively. The internal structure and the progress of the synthesis were assessed by transmission electron microscopy (TEM; JEM-2100) performed at an acceleration voltage of $200 \mathrm{kV}$. Samples were sonicated in ethanol before being dropped on a copper mounted holey carbon film and dried. The statistical characterization of the diameter size distribution of each sample was performed based on the TEM images. Thermalgravimetric analysis (TGA) and was conducted on a TA Instruments Q500 thermal analyzer apparatus under an ambient atmosphere. The infrared (IR) spectrum instrument is a TENSOR 27 instrument. The surface area (BET) and pore volume and size $(\mathrm{BJH})$ of the materials was determined 
Cite this: DOI: $10.1039 / \mathrm{c0xx00000x}$

ARTICLE TYPE

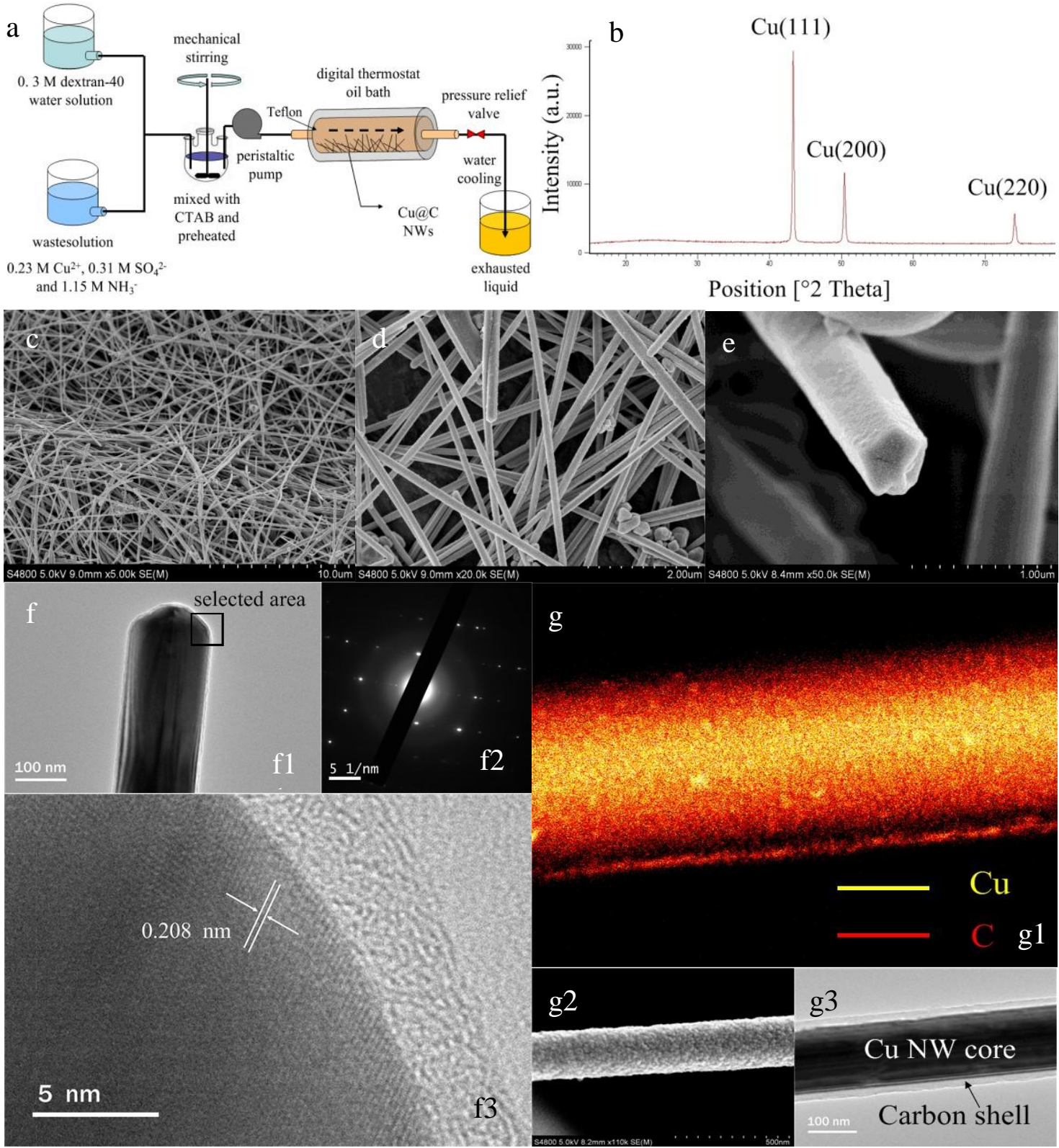

Figure 1. a) Schematic of the CFR for $\mathrm{Cu} @ \mathrm{C}$ NW growth. b) XRD-pattern of the as-obtained fresh products after dried in the atmosphere of nitrogen. c-e) SEM images of Cu@C NWs at different magnifications, which show ultralong Cu@C NWs with diameter of 100-180 nm and lengths over 20 $\mu \mathrm{m}$. f) Top left inset $\mathrm{f} 1$ is bright-field TEM image of an individual $\mathrm{Cu} @ \mathrm{C}$ NW (side view), top right inset $\mathrm{f} 2$ is the corresponding SAED pattern which reflects standard fcc-structured copper and the bottom image $\mathrm{f} 3$ shows high-resolution TEM image of an individual Cu NW from selected area, clearly showing a lattice spacing of $0.209 \mathrm{~nm} . \mathrm{g}$ ) EDX-analysis of a Cu NW, g1 is elements superimposed mapping results and g2, g3 are corresponding SEM and TEM images, respectively.

by nitrogen sorption (Tristar 3000, Micromeritics Instrument Corporation, U.S.A) at $-195.7^{\circ} \mathrm{C}$. The Raman spectrum was recorded at room temperature on a LABRAM-010 Confocal Laser Micro-Raman spectrometer (Jobin Yvon). Cyclic voltammetric (CV) and amperometric measurements were performed in a dual channel electrochemical workstation (CHI832C) with which a conventional three electrode cell was connected. A copper based nanomaterials modified electrodes, a platinum wire electrode and a $\mathrm{Ag} / \mathrm{AgCl}(3 \mathrm{M} \mathrm{NaCl})$ electrode served as the working electrode, counter electrode, and reference electrode, respectively. $50 \mathrm{mM} \mathrm{NaOH}$ solution was applied as the electrolyte in the study, which would provide a general view regarding the electrochemical behavior of the modified electrodes. 


\section{Results and discussion}

\subsection{Characterization of as-prepared $\mathrm{Cu} / \mathrm{C}$ composites nanomaterials.}

Figure 1a shows the schematic diagram of the preparation procedure for the $\mathrm{Cu} @ \mathrm{C}$-amorphous core-shell nanowires through a CFR system. The formation of metallic copper nanowires in this work is based on the reduction of $\mathrm{Cu}^{2+}$ ions (the oxidizing reagent) by the aldehyde group of reducing reagent dextran:

$$
\begin{gathered}
\mathrm{H}\left(\mathrm{C}_{6} \mathrm{H}_{10} \mathrm{O}_{5}\right) \mathrm{nOH}+\mathrm{Cu}\left(\mathrm{NH}_{3}\right)_{2}(\mathrm{OH})_{2} \rightarrow \\
\mathrm{H}\left(\mathrm{C}_{6} \mathrm{H}_{10} \mathrm{O}_{5}\right)_{\mathrm{n}-1} \mathrm{C}_{5} \mathrm{H}_{10} \mathrm{O}_{5} \mathrm{COONH}_{4}+\mathrm{Cu}+\mathrm{NH}_{3} \uparrow+\mathrm{H}_{2} \mathrm{O}
\end{gathered}
$$

The dextran plays dual roles in the reaction. According to the abundance in the polarity hydroxyl and ether oxygen groups content, it is intrinsically a ligand capable of complexing with $\mathrm{Cu}^{2+}$ and lowering the activity (supersaturation) of them, which prevents the grains over growth. Then the resulting metal nanoparticles act as catalysts of the carbonization process of the glucose chains. Moreover, CTAB, as a strong surface capping agents, is also introduced onto the specific facet of the nanostructure and leaving the bare facet still active for the further deposition of copper atoms thus further guide the anisotropic growth of these $\mathrm{Cu} @ \mathrm{C}$ NWs. The morphology and dimensions of the as-prepared $\mathrm{Cu} @ \mathrm{C}$ NWs were observed by scanning electron microscope (SEM). Figure 1c-e show ultralong and well dispersed Cu@C NWs with an outer diameter of 100-180 nm and a length up to tens of micrometers. The NWs tend to be entangled with each other after centrifugation (Figure S1), which is different from pure $\mathrm{Cu}$ NWs fabricated by polyol process ${ }^{[22]}$ that are well dispersed. This characteristic certainly will affect their electrochemical properties while this condition can be improved by properly adjusting the loading amount of NWs as mentioned later. X-ray diffraction (XRD, Figure 1b) confirms that the as-synthesized NWs are face-centered cubic (fcc) $\mathrm{Cu}$ with a calculated lattice constant $a=3.6187 \AA$ (PDF 04-0836, $a=0.3615$ $\mathrm{nm})$. And the XRD patterns revealed in Figure S2 indicated that the as-prepared sample was unchanged after storage for 1 year in the ambient environment which declare their better stability than $\mathrm{Cu}$ NWs. Element analysis of the NWs was performed using both energy dispersive X-ray (EDX) spectroscopy (Figure S3) and its mapping analysis across the axis of a single NW (Figure 1g), which unambiguously confirms $\mathrm{C}$ and $\mathrm{Cu}$ exist in the $\mathrm{NW}$ that the amorphous carbon is allocated to the sheath that wraps the core consisting of copper. Transmission electron microscopy (TEM) characterization was carried out to further confirm the phase identity of the $\mathrm{Cu} @ \mathrm{C}$ NWs (Figure. 1f). The lattice fringe distance of $2.08 \AA$ (fitted well with the result of calculated crystal size $\mathrm{D}=0.2089 \mathrm{~nm}$ based on XRD data) could be ascribed to the $\{111\}$ reflection of fcc $\mathrm{Cu}$, which suggests the features of a single-crystal $\mathrm{Cu}$ phase. It is also clearly observed from the HRTEM image that surfaces of the $\mathrm{Cu}$ NWs are coated with an amorphous carbon layer with a thickness of about 3-8 nm, proving the existence of carbon coating. The spot feature of the corresponding selected area electron diffraction (SAED) pattern of the same $\mathrm{Cu}$ NW (Figure. 1f2) further indicates that it is a piece of single crystal growing along the $\{110\}$ direction with $\{100\}$ facets exposed on the side surface.

To investigate the effect of the coating carbon structure on glucose oxidation performance, we have also explored the

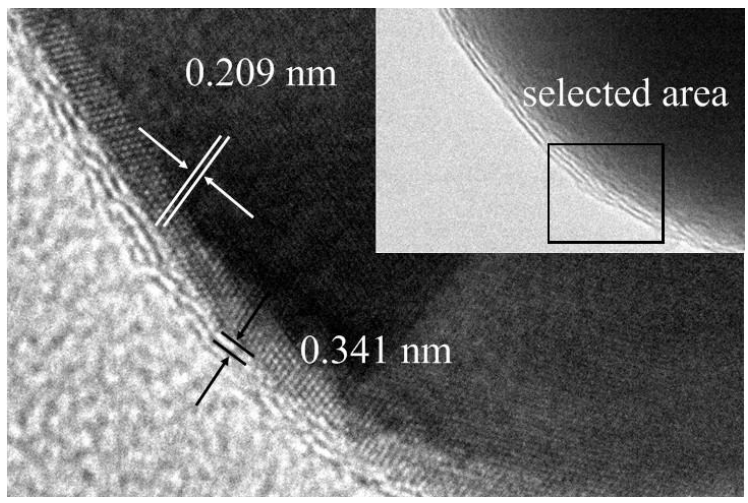

Figure 2. HRTEM image of copper/graphite carbon interface on the surface of $\mathrm{Cu} \mathrm{NW}$ core from the top right inset selected area.

MOCVD method to form vertical arranged $\mathrm{Cu}$ NWs wrapped in graphene shells for comparison (see ESI 1.1). The as-grown graphite carbon, with many wrinkles, fully covered the entire $\mathrm{Cu}$ core surface investigated by low- and high-magnification TEM as illustrated in Figure 2. The wrinkle formation was due to the thermal expansion coefficient difference between the $\mathrm{Cu}$ and the graphene shells. Further HRTEM examination on individual $\mathrm{Cu} @ \mathrm{C} N W$ shows that the d-spacing of the graphite layers (2-3 layers, $\mathrm{d}(002)=0.34 \mathrm{~nm}$ ) and encapsulated $\mathrm{Cu}$ crystals with (111) atomic plane $(\mathrm{fcc}, \mathrm{d}(111)=0.209 \mathrm{~nm})$. Figure $\mathrm{S} 4 \mathrm{~b}$ shows a typical morphology of these $\mathrm{Cu} @ \mathrm{C}$-graphire NWs, which were straight with diameters of $\approx 80-150 \mathrm{~nm}$, and having length of dozens of microns. The XRD pattern shown in Figure S4a also reveals that the $\mathrm{Cu}$ NWs are in fcc phase with a lattice constant of $3.6157 \AA$, which is very close to the value of pure copper too. In addition, the peaks from $20-28^{\circ}$ correspond to diffraction of graphite can be observed, which further confirms the diffraction signals are from small amounts of graphene layers.

The thermal stability and reaction activity with oxygen of the as-grown sample was studied by TG-DTA (Figure 3b). It is obvious that the initial weight loss below $200{ }^{\circ} \mathrm{C}$ is due to the removal of adsorbed water and combustion of organic ligands containing hydrocarbon tail on $\mathrm{Cu}$ nanocores, which can be proved by enhanced at $2869 \mathrm{~cm}^{-1}, 2924 \mathrm{~cm}^{-1}$ and $1601 \mathrm{~cm}^{-1}$ in the IR attribute to functional groups such as $\mathrm{C}-\mathrm{H}, \mathrm{C}-\mathrm{O}$, and $\mathrm{C}=\mathrm{C}$ groups inherited from glucose were reduced after calcined (Figure 3a). Furthermore, it can also be observed from the TG curve that a distinct weight gain emerged in the $200-400^{\circ} \mathrm{C}$ range, however, the curve around $260-310^{\circ} \mathrm{C}$ was a little indent, which reflect a combination of weight loss (arising from the conversion from the exterior carbonaceous shell to $\mathrm{CO}_{2}$ on the basis of FTIR analysis) and weight gain (arising from the oxidation of $\mathrm{Cu}$ core to $\mathrm{CuO}$ ). It's important to note that the carbonaceous shell (3-8 $\mathrm{nm})$ obtained in our experiment was dramatically thinner than the $\mathrm{Cu}$ core $(\sim 150 \mathrm{~nm})$, which resulted in the larger relative quantities of $\mathrm{Cu}$ to $\mathrm{C}$ in contrast with that of the previous report ${ }^{[31]}$ about the $\mathrm{Cu} @ \mathrm{C}$ cable composites prepared in autoclave (in which the thicknesses of the shell and core were nearly $\sim 30$ and $\sim 90 \mathrm{~nm}$, respectively, and the remarkable weight loss occurred in the 400$750^{\circ} \mathrm{C}$ range), thus the weight loss is neglected by the increase of element $\mathrm{O}$ in present work, and finally the trend of the TGA curve were different in these two cases. Herein it can be seen that the thickness of carbon shells is a very important issue for NWs oxidation activity. DTA curves were used to further estimate the 

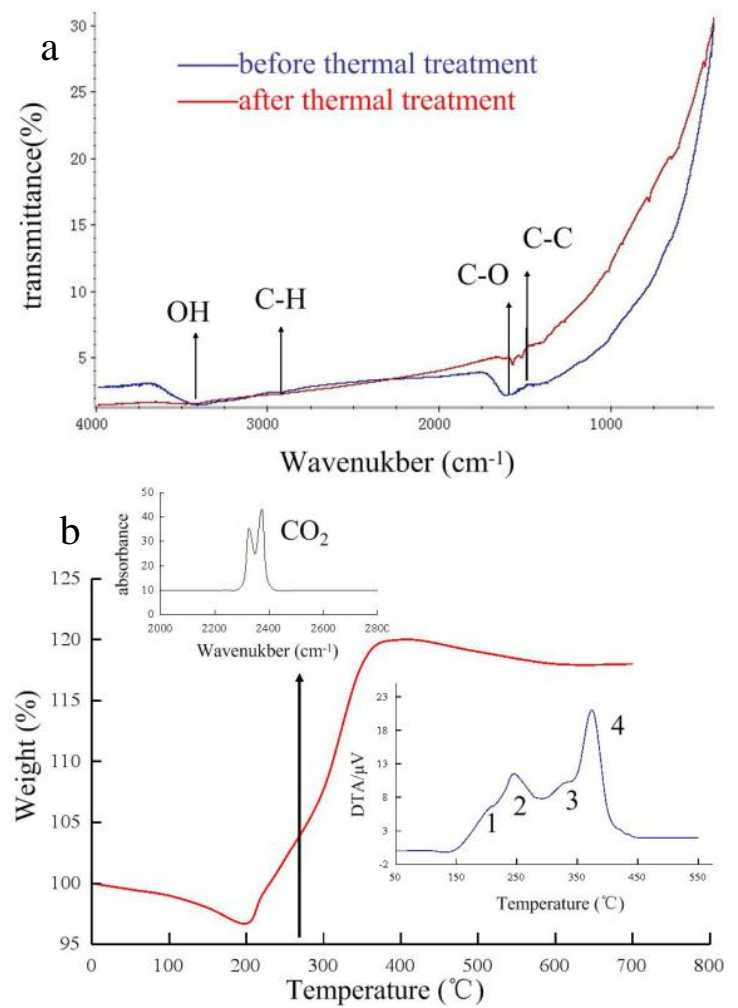

Figure 3. (a) Typical IR spectrum comparison of the $\mathrm{Cu} @ \mathrm{C}$ NWs before and after calcination; (b) Thermogravimetric (TG) and differential thermal analysis (DTA) curve (bottom right insert) of the Cu@C NWs composites in ambient atmosphere, and top left insert of (b) is IR analysis of releasing gas in TG process contribute to $\mathrm{CO}_{2}$ around $260-310^{\circ} \mathrm{C}$

chemical process during thermal analysis, which can be resolved into four prominent exothermic peaks (bottom-right of Figure 3b). Component 1 (at $190-200^{\circ} \mathrm{C}$ ) and 2 (at $260-310^{\circ} \mathrm{C}$ ), indicating a rapid combustion, is attributed to surfactant combustion as previously mentioned. Component 3 and 4 (corresponding to the obvious weight increasment around $300-450{ }^{\circ} \mathrm{C}$ concern the oxidation heat liberation corresponding to $\mathrm{Cu} \rightarrow \mathrm{Cu}_{2} \mathrm{O}$ and $\mathrm{Cu}_{2} \mathrm{O}$ $\rightarrow \mathrm{CuO}$. Both the TG and DTA curves imply that the $\mathrm{Cu} @ \mathrm{C} \mathrm{NWs}$ are easier to be oxidized at relatively lower temperatures.

Besides $\mathrm{Cu} @ \mathrm{C}$ NWs, most recently, nanomaterials such as CNTs combined with transition metallic NPs have also been widely applied in sensors and biosensors, due to their increased electrochemical activities with high surface area, enhanced mass transport and catalysis. ${ }^{[32-35]}$ For quick references, the sensor with electrode positing the $\mathrm{Cu}$ nanoclusters onto the electrode modified with Nf-solubilized CNTs reveal good performances. However, these $\mathrm{Cu}$ NPs do not have good stability for long-term electroanalysis and their synthesis is time-consuming and complicated. Thus we developed the current method to synthetize Cu@C NPs embed onto MWCNTs (see ESI 1.2), not only for facilitating preparation technology, more importantly, but also for comparison with $\mathrm{Cu} @ \mathrm{C} \mathrm{NWs}$ to reflects its further superiority. Therefore, this work is so expected for subsequent investigation. The $\mathrm{Cu}$ NPs/MWCNTs were characterized by TEM as illustrated in Figure $4 \mathrm{a}$, revealing that $\mathrm{Cu}$ nanoclusters were deposited on the CNTs matrix and that the size can range from 5 to $65 \mathrm{~nm}$. The thickness of the carbon shell is in the range of 3-5 nm, which can prevent the $\mathrm{Cu}$ core from being oxidized or aggregated, indicating
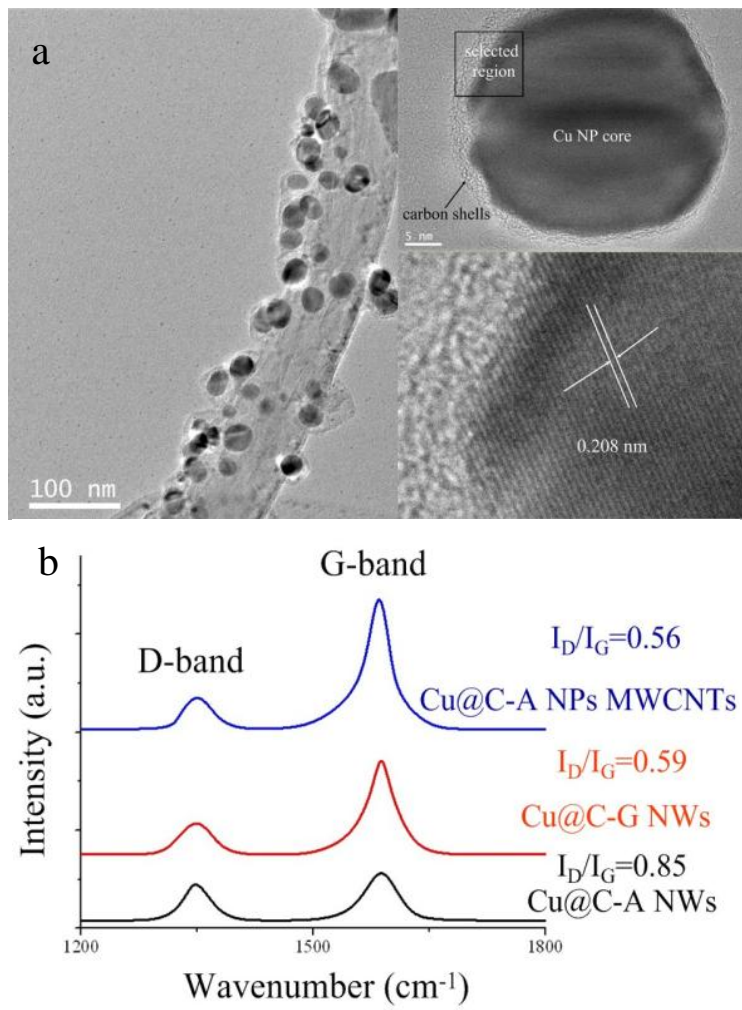

Figure 4. a) High-resolution TEM image of one single MWCNT adhered by NPs, and the bottom right inset of (a) is HRTEM characterizations of a $\mathrm{Cu} @ \mathrm{C}$ NP from selected area of the illustration at top-right. b) Raman spectra of carbon shells grown on different $\mathrm{Cu}$ crystals composites.

that these $\mathrm{Cu}$ NPs having a moderate dispersion. The as-prepared nanocomposites feature was also demonstrated by using power XRD (Figure S6a). The diffraction pattern clearly shows not just three major peaks which can be assigned to the diffraction from the $\{111\},\{200\}$, and $\{220\}$ planes of the fcc lattice of $\mathrm{Cu}(0)$ but an additional peak of $25.896^{\circ}$ is attributed to the $\{002\}$ phase of the CNTs. On the existing basis, Figure $4 \mathrm{~b}$ depicts the Raman spectrum of these three $\mathrm{Cu} / \mathrm{C}$ based nanomaterials to assess the defects in the structure and crystallinity of core-shell structured carbon sheath encapsulated metal materials, fitting of the spectral region, G-band peak around $1560 \mathrm{~cm}^{-1}$ due to the inplane oscillations of $\mathrm{sp}^{2}$ carbon atoms in carbon shells and D-band peak around $1360 \mathrm{~cm}^{-1}$ due to the presence of defects in sheaths. In amorphous carbons $\mathrm{I}(\mathrm{D}) / \mathrm{I}(\mathrm{G})$ (the intensity ratio of the $\mathrm{D}$ and $\mathrm{G}$ peaks) is a measure of the size of the $\mathrm{sp}^{2}$ phase organized in rings. If $\mathrm{I}(\mathrm{D}) / \mathrm{I}(\mathrm{G})$ is negligible, then the $\mathrm{sp}^{2}$ phase is mainly organized in chains, or, even if rings are present, the $\pi$ bonds are not fully delocalized on the rings, indicating that lesser the structural defects in shells would be ${ }^{[36,37]}$. The broadened and downshift feature centered at $1340 \mathrm{~cm}-1$ (D band) confirms that the degree of disorder in carbon shell is increasing from $\mathrm{Cu} @ \mathrm{C}$ NPs/MWCNTs to $\mathrm{Cu} @ \mathrm{C}$ NWs. Having considered the overall design of different nanostructures we can now move to consider the effects may it have for their sensor performances.

\subsection{Electrochemical characterization.}

The typical current-voltage behavior of a $\mathrm{Cu} @ \mathrm{C}-\mathrm{A}$ NWs modified electrode in strongly alkaline solution $(50 \mathrm{mM} \mathrm{NaOH})$ in the presence and absence of glucose are illustrated by the 


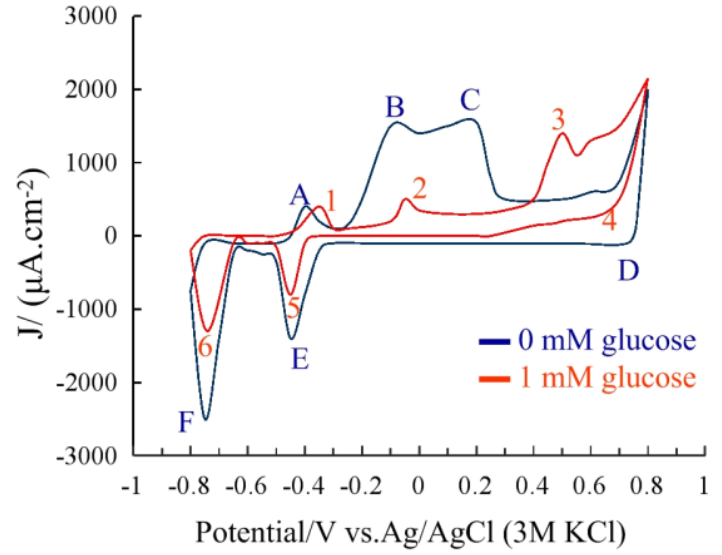

Figure 5. Cyclic voltammograms of $\mathrm{Nf} / \mathrm{Cu} @ \mathrm{C}-\mathrm{A} \mathrm{NWs} / \mathrm{GCE}$ in the absence and the presence of $1.0 \mathrm{mM}$ glucose in $50 \mathrm{mM} \mathrm{NaOH}$ solution at scan rate of $5 \mathrm{mV} / \mathrm{s}$.

cyclic voltammogram shown in Figure 5, and the scan rate is 5 $\mathrm{mV} / \mathrm{s}$. For the cyclic voltammogram $(\mathrm{CV})$ in the present of glucose, all the six peaks/waves can be assigned to the corresponding electrochemical process according to the literature. The anodic peaks labeled 1 at $-0.39 \mathrm{~V}$ represent the transition of $\mathrm{Cu}(0)$ to $\mathrm{Cu}(\mathrm{I})$, the anodic peaks labeled 2 at $-0.15 \mathrm{~V}$ results from the transition of $\mathrm{Cu}(\mathrm{I})$ to $\mathrm{Cu}(\mathrm{II})$ and oxidation of metallic $\mathrm{Cu}$ to $\mathrm{Cu}$ (II). The third redox peak was seen centered at $+0.49 \mathrm{~V}$, which is considered to be related with the desorption of glucose from $\mathrm{Cu}(\mathrm{I})$ and the transition of $\mathrm{Cu}(\mathrm{I}) / \mathrm{Cu}(\mathrm{II})$ shifting from the peak $\mathrm{C}$ compared with the $\mathrm{CV}$ in the absence of glucose, and this is the major difference between the two. In a circumstance where glucose exists, the adsorption of glucose on the surface of the catalyst occurs, which could block the contact between the $\mathrm{Cu}$ based solid(s) and hydroxide ions. But in the absence of the glucose the third peak was usually seen at potentials just after the onset of the second peak B, presumably, these waves correspond to the formation of soluble species from the $\mathrm{Cu}$-based solid(s) and hydroxide ions because of the loss of surface protection. In addition, the cathodic peaks labeled 4 at around $+0.6 \mathrm{~V}, 5$ at -0.42 $\mathrm{V}$ and 6 at $-0.73 \mathrm{~V}$ correspond to the transition of $\mathrm{Cu}(\mathrm{III}) / \mathrm{Cu}$ (II), $\mathrm{Cu}(\mathrm{II}) / \mathrm{Cu}(\mathrm{I})$, and $\mathrm{Cu}(\mathrm{I}) / \mathrm{Cu}(0)$, respectively, and the electrooxidation of glucose occurs in the potential range of 0.40 to $0.8 \mathrm{~V}$. With the purpose of estimating the applicability of $\mathrm{Cu} @ \mathrm{C}-\mathrm{A}$ NWs in non-enzymatic glucose sensing, a series of simplified analyses were carried out in the potential ranging from $+0.2 \mathrm{~V}$ to $+0.8 \mathrm{~V}$ at a scan rate of $50 \mathrm{mV} / \mathrm{s}$ which is ideal for quantitative analysis in practical applications. As a comparison illustrated in Figure S7a, increase of anodic current can be observed with the increment of glucose from 0 to $6 \mathrm{mM}$ on the Nafion/Cu@C-A NWs/GCE. Moreover, when using Nafion/GCE under the same condition the increase of the anodic current are less dramatically than that of Nafion/Cu@C-A NWs/GCE, which confirms the as-embellished electrode was more sensitive. In order to improve its performance, it should also be noted that the specific characteristics of these CVs are strongly dependent on the hydroxide concentration used and the appropriate amount of $\mathrm{Cu} @ \mathrm{C}-\mathrm{A}$ NWs loaded on the transducer. Therefore, various factors affecting the response of the sensor were investigated. The results show that the influence of increasing the $\mathrm{NaOH}$ concentration on the response current of the sensor is similar as

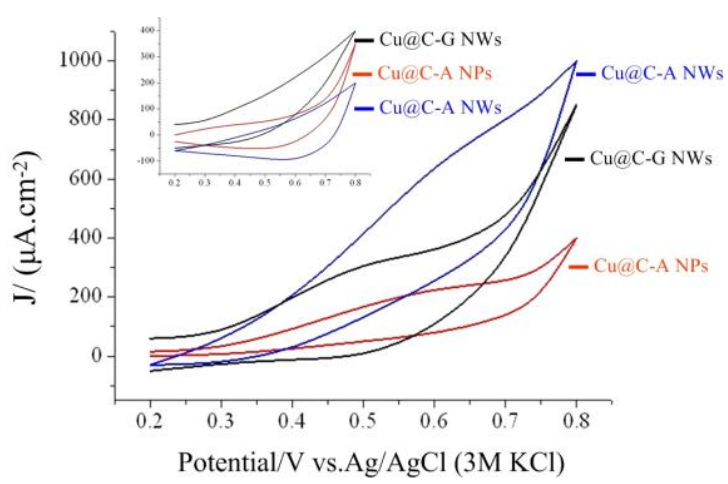

Figure 6. CVs of $\mathrm{Cu} @ \mathrm{C}-\mathrm{A}$ NWs, Cu@C-G NWs and $\mathrm{Cu} @ \mathrm{C}-\mathrm{A}$ NPs modified electrodes without glucose (inset), and with $2 \mathrm{mM}$ glucose in 20 $\mathrm{mM} \mathrm{NaOH}$ at scan rate of $50 \mathrm{mV} / \mathrm{s}$.

increasing glucose (Figure S7b), but further increase of the concentration of $\mathrm{NaOH}$ to $0.1 \mathrm{M}$ gives only moderate increase of the current which may be attributed to the limited loading of $\mathrm{Cu} @ \mathrm{C}-\mathrm{A}$ NWs on the GCE. Figure S8 presents the effect of the $\mathrm{Cu} @ \mathrm{C}-\mathrm{A}$ NWs loading on the response of the glucose sensor that the response could not keep on increasing state but falls when $\mathrm{Cu} @ \mathrm{C}$-A NWs loading is higher than $60 \mu \mathrm{g}$, the reason is ascribed to the excessive addition of $\mathrm{Cu} @ \mathrm{C}-\mathrm{A}$ NWs will decrease the adsorption sites with glucose arising from mutual interlacing and obscuration, thus the effect will not be ideal. Herein, a Cu@C-A NWs loading of $60 \mu \mathrm{g}$ was used in the subsequent work. In particular, preparation temperature was also an important factor affecting performances as glucose sensor due to some conspicuous structural variances, we have investigated the influence of reaction temperature on the formation of $\mathrm{Cu} @ \mathrm{C}$ NWs at 140,160 , and $170{ }^{\circ} \mathrm{C}$ respectively. The result reveals that the products prepared at $140{ }^{\circ} \mathrm{C}$ containing $16 \%$ of nanowires, almost $45 \%$ of irregular blocky nanoparticles and $39 \%$ of spherical macro-nanoparticles due to the lower activity of the system when the temperature was below $150{ }^{\circ} \mathrm{C} ; 65 \%$ nanowires and $35 \%$ irregular nanoparticles at $160^{\circ} \mathrm{C}$ because of molecular motion is more intense if the temperature is increased up to $160^{\circ} \mathrm{C}$ that makes the adsorption of CTAB unstable on the (100) crystal surface and the yield of nanowires is also unsatisfactory compared with products fabricated at $150{ }^{\circ} \mathrm{C}$; and the nanowires obtained at $170{ }^{\circ} \mathrm{C}$ are totally bending to reduce the intrinsic energy. The structural variation of each activity under various temperature are illustrated in Figure S9. In Figure S10, an overview of electrochemical properties for sensing glucose results is presented. As expected, during the potential scan from $0.2 \mathrm{~V}$ to $0.8 \mathrm{~V}$, no obvious oxidation peaks were observed for glucose at the $1400^{\circ} \mathrm{C}$ and $170^{\circ} \mathrm{C}$ products modified electrodes, suggesting that the oxidation activity of glucose is very poor. It can be attributed to the decrease of electroactive surface area, inferior conductivity for efficient electron transfer and poor adsorbtion ability as a result of the lack of the three-dimensional porous structure on the surface of carbon shells. By comparison, it also shows significantly higher reduction/oxidation responses of of electrodes embellished with $150^{\circ} \mathrm{C}$ products than the $160^{\circ} \mathrm{C}$ products do, which was owing to the interference of increasing by-products.

To compare electrocatalysis of glucose oxidation by the Cu@C-A NWs electrodes, CV studies of Cu@C-G NWs, and 


\section{Cite this: DOI: 10.1039/c0xx00000x}
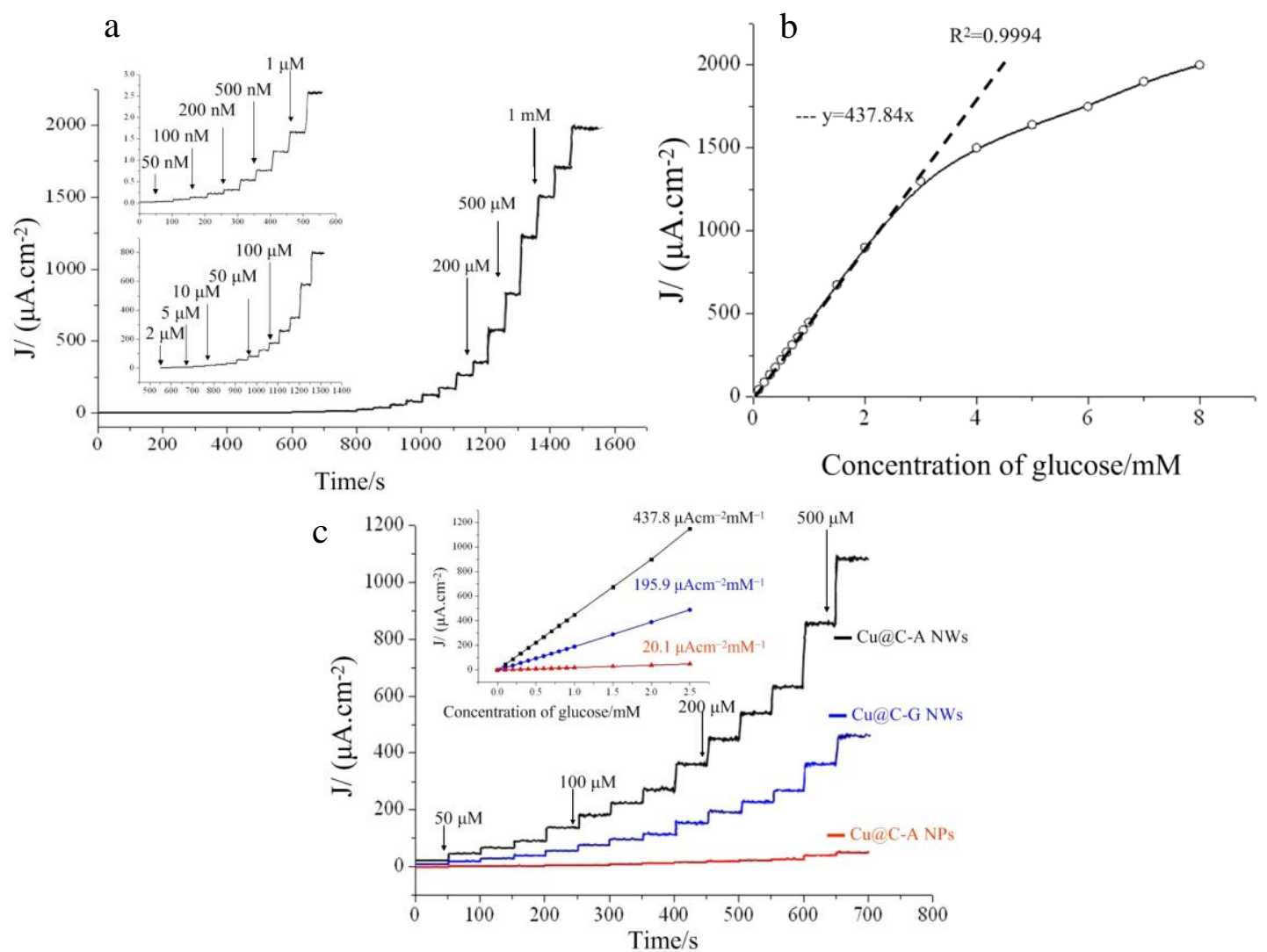

Figure 7. a) Amperometric responses of $\mathrm{Cu} @ \mathrm{C}-\mathrm{A}$ NWs electrodes at $0.65 \mathrm{~V}$ to successive additions of glucose from $50 \mathrm{nM}$ to $1 \mathrm{mM}$ (double injections per concentration) in $50 \mathrm{mM} \mathrm{NaOH}$. b) Current responses to glucose concentrations from the data in a). c) Amperometric responses of three electrodes modified by different nanocomposites in $50 \mathrm{mM} \mathrm{NaOH}$ with successive additions of glucose from $50 \mu \mathrm{M}$ to $500 \mu \mathrm{M}$ (quadruple injections per concentration until accumulative concentration reaches $2.5 \mathrm{mM}$ ), and inset is the current response vs. glucose concentration at different electrode indicating various sensitivities.

Cu@C-A NPs/MWCNTs electrodes were also performed. As shown in Figure 6, in a alkaline solution $(50 \mathrm{mM} \mathrm{NaOH})$ mixed with $2 \mathrm{mM}$ glucose, dramatic enhancement of the oxidation current can be observed between 0.25-0.8 V, 0.55-0.8 V, and 0.60.8 V for the Cu@C-A NWs, Cu@C-G NWs, and Cu@C-A NPs/MWCNTs modified electrodes, respectively. As can be seen from the above results, compared to the other electrodes we fabricated in the current study and blank electrode, $\mathrm{Cu} @ \mathrm{C}-\mathrm{A}$ NWs electrode exhibited substantially higher current. Furthermore, obvious negative shift in peak potential and big wider range of potential can also be observed especially in comparison with bare Nf/GCE, suggesting a stronger electrocatalytic activity of $\mathrm{Cu} \mathrm{NWs}$ core on the direct oxidation of glucose, which is considered to be the result of a larger surface area and higher conductivity as well as fast electron transfer provided by oriented mettalic nano-copper than NPs and CNTs.

The real-time amperometric detection of glucose on the Nf/GCE through surface modification by using different asprepared nanostructures were carried out by successive injections of glucose (from $50 \mathrm{nM}$ to $1 \mathrm{mM}$ and double injections per concentration) into $50 \mathrm{mM} \mathrm{NaOH}$ solution at an applied potential of $+0.65 \mathrm{~V}$ and compared in Figure 7. As expected, the $\mathrm{Cu} @ \mathrm{C}-\mathrm{A}$ NWs modified electrode showed good linear response to the changes of glucose concentration (Figure 7a). It took within 5 s to achieve the steady-state current, indicating the fast amperometric response of the modified electrode. And the calibration curve for the glucose sensor is presented in Figure $7 \mathrm{~b}$, which gives a linear response up to $3 \mathrm{mM}\left(\mathrm{R}^{2}=0.9994\right)$ with a fast response, a sensitivity of $437.8 \mu \mathrm{Acm}^{-2} \mathrm{Mm}^{-1}$, and a limit of detection as low as $50 \mathrm{nM}$. The response is gradually saturated at a higher glucose concentration. Conspicuously, the detection limit, sensitivity, and applied potential obtained from present work exhibit comprehensive superior performance than the results from other $\mathrm{Cu}$-based nanomaterials as summarized in Table 1. Furthermore, the sensitivity of Nf/Cu@C-A NWs/GCE is much higher than that of the control electrode Nf/GCE (Figure S11) and noticeably, is also higher than the results from Nf/Cu@C-G NWs/GCE (195.9 $\left.\mathrm{\mu} \mathrm{Am}^{-2} \mathrm{Mm}^{-1}\right)$, and Nf/Cu@C-A NPs/CNTs/GCE (20.1 $\mu \mathrm{Acm}^{-2} \mathrm{Mm}^{-1}$ ) under their optimization conditions (Figure $7 \mathrm{c}$ ). Although the exact mechanism for the oxidation of glucose in alkaline media at $\mathrm{Cu} @ \mathrm{C}-\mathrm{A}$ NWs electrodes is still not known with certainty, we anticipate the performance may be improved 
Cite this: DOI: $10.1039 / \mathrm{c0xx} 00000 \mathrm{x}$

wWw.rsc.org/xxxxxx

ARTICLE TYPE

Table 1. Comparison of the analytical performance of various hottest $\mathrm{Cu}$ based glucose sensors.

\begin{tabular}{|c|c|c|c|c|}
\hline Electrodes & $\begin{array}{c}\text { limit of detection } \\
(\mathrm{nM})\end{array}$ & $\begin{array}{c}\text { Sensitivity } \\
\left(\boldsymbol{\mu A} \mathbf{~ m M}^{-1} \mathbf{c m}^{-2}\right)\end{array}$ & $\begin{array}{c}\text { Applied potential } \\
\text { (V) }\end{array}$ & Reference \\
\hline \multicolumn{5}{|c|}{ Cu nanostructures } \\
\hline $\mathrm{Cu} @ \mathrm{C}$ composite nanotube array & 1000 & 1200 & -0.2 & 38 \\
\hline Cu@PPy NWs & 1000 & 180.65 & 0.7 & 39 \\
\hline $\mathrm{Cu}$ NWs & 35 & 420.3 & 0.6 & 28 \\
\hline Cu@C NWs & 50 & 437.8 & 0.65 & Present work \\
\hline $\mathrm{Cu} \mathrm{NBs}^{\mathrm{b}}$ & 10000 & 79.8 & 0.6 & 40 \\
\hline \multicolumn{5}{|c|}{ Cu-CNT composites } \\
\hline $\mathrm{Cu}$ nanocluster/MWCNTs ${ }^{\mathrm{e}}$ & 210 & 17.76 & 0.65 & 33 \\
\hline $\mathrm{GC}^{\mathrm{c}} / \mathrm{MWNTs} / \mathrm{Cu}$ & 600 & 150 & 0.8 & 41 \\
\hline $\mathrm{Cu} / \mathrm{CNT}$ film & 100 & 40 & -0.03 & 42 \\
\hline $\mathrm{Cu}$ NPs/Au NPseed/CNTs & 30 & 60.38 & 0.65 & 18 \\
\hline $\mathrm{Cu}$ NPs/SWCNTs ${ }^{\mathrm{f}}$ & 250 & 256 & 0.65 & 32 \\
\hline $\mathrm{Cu}$ NPs/graphene & 500 & N/A & 0.5 & 35 \\
\hline $\mathrm{Cu}$ NPs/MWCNTs ${ }^{\mathrm{e}}$ & 500 & 50.47 & 0.35 & 27 \\
\hline \multicolumn{5}{|c|}{$\mathrm{Cu}$ oxides composites } \\
\hline $\mathrm{Cu}_{2} \mathrm{O} / \mathrm{SWCNTs}^{\mathrm{f}}$ & 200 & 2143 & 0.4 & 43 \\
\hline $\mathrm{CuONWs}$ & 490 & 490 & 0.33 & 44 \\
\hline $\mathrm{CuO}$ fibers & 800 & 431.3 & 0.4 & 45 \\
\hline $\mathrm{CuO} \mathrm{NPs}$ & 2400 & 629 & 0.75 & 46 \\
\hline CuxO flowers & 49000 & 1620 & 0.5 & 47 \\
\hline $\mathrm{CuO}$ NPs/MWCNTs ${ }^{\mathrm{e}}$ & 200 & 2596 & 0.4 & 48 \\
\hline
\end{tabular}

${ }^{\mathrm{a} P P y}$-polymer poly-pyrrole, ${ }^{\mathrm{b}} \mathrm{NBs}$-nanobelts, ${ }^{\mathrm{c}} \mathrm{GC}$-glassy carbon, ${ }^{\mathrm{d}} \mathrm{NPs}$-nanoparticles, ${ }^{\mathrm{e}} \mathrm{MWCNTs-multiwall} \mathrm{carbon}$ nanotubes, ${ }^{\mathrm{f}} \mathrm{SWCNTs-singlewall}$ carbon nanotubes

further upon additional prominent conductivity of metallic $\mathrm{Cu}$ NWs core that allowing long range electron transfer between the glassy carbon and the analyte and good electrocatalytic activity of the $\mathrm{Cu} @ \mathrm{C}$ nanohybrids. The existence of activated carbon combined with nanoocpper greatly increases the electrocatalytic active sites and adsorption areas and promote electron transfer in the oxidation of glucose. The pore size distributions of the $\mathrm{Cu} @ \mathrm{C}-\mathrm{A}$ sample calculated from the adsorption branches of nitrogen isotherms by the Barrett-Joyner-Halenda $(\mathrm{BJH})$ is illustrated in Figure S12, which confirms that pores diameters are centered within $2.5 \mathrm{~nm}$ and it's big enough for the permeation of glucose molecule $(\leq 0.7 \mathrm{~nm})$. The $\mathrm{Cu} @ \mathrm{C}$-A NWs exhibited a Brunauer-Emmett-Teller (BET) surface area of $8.02 \mathrm{~m}^{2} \mathrm{~g}^{-1}$ and a total pore volume of $0.0057 \mathrm{~cm}^{3} \mathrm{~g}^{-1}$. The inset of Figure $\mathrm{S} 12$ is the glucose adsorption curve with increasing adsorption time on Cu@C-A NWs, as one can see that the adsorbance increases as time extends and attains over $65 \mu \mathrm{g} / \mathrm{g}$ in 5 hours. So there seems to be a significant capture of glucose on the surface of $\mathrm{Cu} @ \mathrm{C}$-A NWs preferentially, after the gradually saturation of exploitable sites and then followed by diffusion inside the pores. The SEM image (Figure S12b) at high magnification also showed randomly distributed micropores or cracks of $\sim 3 \mathrm{~nm}$ in the shells which accord well with the nitrogen adsorption/desorption experimental results (Figure S12a). Whereas the $\mathrm{Cu} @ \mathrm{C}-\mathrm{G}$ NWs shows almost no $\mathrm{N}_{2}$-adsorption response with the increasment of relative pressure and its glucose adsorption measurement is much less swanky too. Therefore, we ascribe the observed scores worse in performance of sensor to the more compact structure of graphite shells on $\mathrm{Cu}$ NWs, which blocked further engagement between target analytes and copper core to a certain extent.

As mentioned in the introduction, many enzyme-free glucose sensors based on noble metal are usually prone to be poisoned by chloride ions and enzymatic glucose detections are quite easily disturbed by oxygen deficit. Hence, in order to investigate the anti-interference ability of the Nf/Cu@C-A NWs/GCE, CVs measurement was carried out in $50 \mathrm{mM} \mathrm{NaOH}$ containing $20 \mathrm{mM}$ $\mathrm{NaCl}$ and under $\mathrm{N}_{2}$-saturated conditions, separately. As illustrated in Figure 8a the voltammetric responses of the $\mathrm{Nf} / \mathrm{Cu} @ \mathrm{C}-\mathrm{A}$ NWs/GCE electrode obtained in $50 \mathrm{mM} \mathrm{NaOH}$ containing $2 \mathrm{mM}$ glucose with and without $20 \mathrm{mM} \mathrm{NaCl}$ (the concentration of chloride ion is about ten times of that of glucose level in real physiological samples) under oxygen saturated situation and 

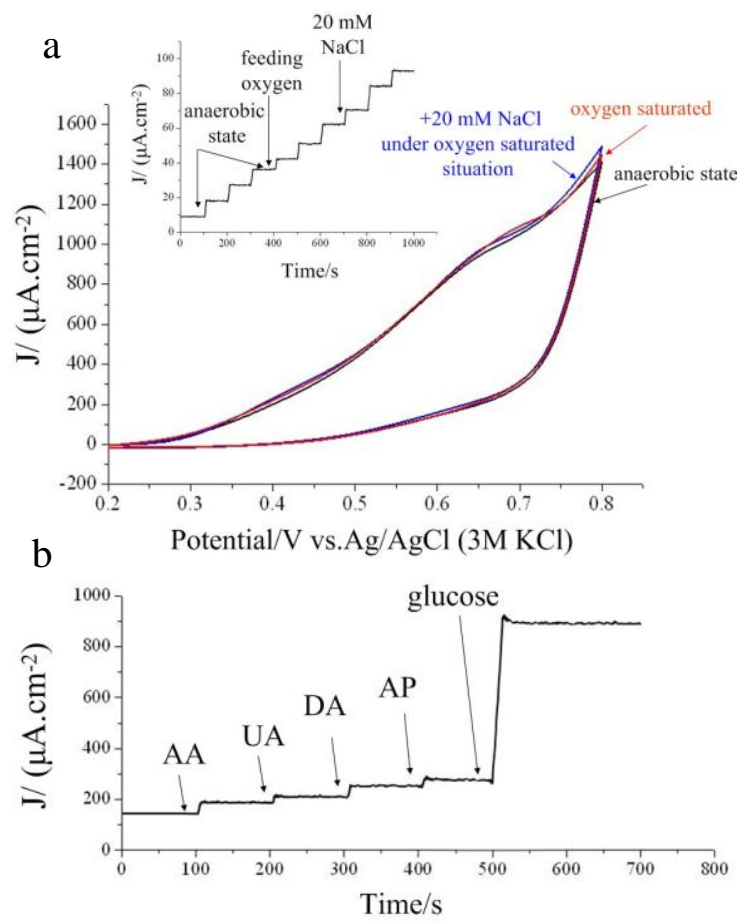

Figure 8. a) $\mathrm{CVs}$ of the $\mathrm{Nf} / \mathrm{Cu} @ \mathrm{C}-\mathrm{A} \mathrm{NWs} / \mathrm{GCE}$ in $50 \mathrm{mM} \mathrm{NaOH}$ containing $2 \mathrm{mM}$ glucose in the presence and absence of $20 \mathrm{mM} \mathrm{NaCl}$ under oxygen saturated situation, and without $\mathrm{NaCl}$ in anaerobic environment (nitrogen saturated) at a scan rate of $50 \mathrm{mV} / \mathrm{s}$. Inset is amperometric response of the Nf/Cu@C-A NWs/GCE to $20 \mu \mathrm{M}$ glucose in $\mathrm{N}_{2}$-saturated $50 \mathrm{mM} \mathrm{NaOH}, \mathrm{O}_{2}$-saturated $50 \mathrm{mM} \mathrm{NaOH}$, and $\mathrm{O}_{2}$ saturated $50 \mathrm{mM} \mathrm{NaOH}$ containing $20 \mathrm{mM} \mathrm{NaCl}$. b) Amperometric responses of the Nf/Cu@C-A NWs/GCE to successive additions of 0.2 $\mathrm{mM}$ AA, $0.2 \mathrm{mM} \mathrm{UA}, 0.2 \mathrm{mM}$ DA, $0.2 \mathrm{mM}$ AP and $2 \mathrm{mM}$ glucose in 50 $\mathrm{mM} \mathrm{NaOH}$ at $0.65 \mathrm{~V}$.

without $\mathrm{NaCl}$ in anaerobic environment are almost identical, declaring that the proposed electrode exhibits good resistance to surface fouling and is promising for development of enzyme-free glucose sensor at low cost. Moreover, interfering species such as L-ascorbic acid (AA), uric acid (UA), dopamineand (DA) and acetaminophen (AP) normally co-exist with glucose in human blood serum and other samples, which also impose a major issue on non-enzymatic glucose sensors. Thus amperometric responses of as-prepared electrode towards the addition of these species (AA, UA, DA and AP: $0.2 \mathrm{mM}$, about one-tenth of the glucose value) followed by glucose ( $2 \mathrm{mM}$ successively) were examined too. According to the results analysis as shown in Figure 8b, all these interfering species do not produce significant responses and the current responses due to the added interferents below $8 \%$ compared to glucose at $0.65 \mathrm{~V}$, indicating that the $\mathrm{Cu} @ \mathrm{C}-\mathrm{A}$ NWs are very favorable for the specific determination of glucose even in the presence of several interfering species. The stability of the developed sensor was examined by measuring its current response to glucose over two months during which only $7 \%$ loss in the current signal was observed (Figure S14), indicating good stability of the sensor. In contrast, the sensor which modified by pure $\mathrm{Cu}$ NWs (Figure S13, synthesized by polyols process earlier ${ }^{[29]}$ ) shows an obvious decrease in the response to glucose as compared with its initial measurement attribute to superficial corrosion and missing-row-type reconstruction induced by oxygen chemisorption in alkaline solutions (Figure S15). These results demonstrate that the proposed sensor provide satisfactory performance and has the potential to be used for routine blood glucose sensing.

\section{Conclusions}

In summary, $\mathrm{Cu} @ \mathrm{C}$ core-shell coaxial nanowires have been successfully prepared via a simple continuous flow wet-chemistry method from electroplating wastewater. This approach not only removes the danger of heavy metals but also obtains useful nanostructure in waste water, which have shown remarkable potential owing to their unique surface morphology and prominent conductivity of metallic copper core. The electrochemical studies by cyclic voltammetry and real-time amperometric measurement reveal that the as-prepared Nafion/Cu@C NWs/GCE exhibit good electrocatalytic responses to glucose in alkaline media with a number of attractive features such as high sensitivity, fast response, stability, and good selectivity compared with the other nanostructures, which can be ascribed to the good catalytic ability, effcient electron transfer of the $\mathrm{Cu}$ NWs core, and novel adsorptivity, large surface areas of amorphous carbon shells. Thus, we anticipate that upon further development, these $\mathrm{Cu} @ \mathrm{C}$ NWs electrodes will perform exceptionally for routine analysis of glucose in real human blood serum samples or for capillary electrophoresis microchip detection of carbohydrates.

\section{Acknowledgments}

This work is supported financially by the National Natural Science Foundation of China (Grant No. 50901090) and China Scholarship Council (CSC, No. 201206450026).

\section{Notes and references}

${ }^{a}$ State Key Laboratory for Heavy Oil Processing, Key Laboratory of Catalysis, CNPC, China University of Petroleum, Qingdao 266555, China. Fax: +86 532 86981295; Tel: +86 532 86981296; 86981856; Email: zfyancat@upc.edu.cn

${ }^{b}$ QLD Micro-and Nanotechnology Centre, Nathan Campus, Griffith University, QLD 4111, Australia.

${ }^{c}$ Oil and Gas Control Center of PetroChina, Dongcheng District, Beijing 100007, China.

$\dagger$ Electronic Supplementary Information (ESI) available: [details of any supplementary information available should be included here]. See DOI: $10.1039 / \mathrm{b} 000000 \mathrm{x} /$

$\$$ Footnotes should appear here. These might include comments relevant to but not central to the matter under discussion, limited experimental and spectral data, and crystallographic data.

1 Vaddiraju S, Burgess DJ, Tomazos I, Jain FC, and Papadimitrakopoulos F. J Diabetes Sci Technol., 2010, 4 (6), 154062.

2 Leon A. Terry, Stephen F. White, and Linda J. Tigwell. J. Agric. Food Chem., 2005, 53 (5), 1309-1316.

3 Akin M, Prediger A, Yuksel M, H?pfner T, Demirkol DO, Beutel S, Timur S, Scheper T. Biosens Bioelectron, 2011, 26 (11), 4532-7.

4 Isao Karube, Tadashi Matsunaga, Satoshi Mitsuda, Shuichi Suzuki. Microbial Electrode BOD Sensors, Biotechnol. Bioeng., 1977, 19, 1535-1547.

5 Geun-Cheol Gil, In-Seop Chang, Byung Hong Kim *, Mia Kim, JaeKyung Jang, Hyung Soo Park 1, Hyung Joo Kim. Biosens. Bioelectron., 2003, 18, 327 - 334.

6 In Seop Chang, Hyunsoo Moon, Jae Kyung Jang, Byung Hong Kim. Biosens. Bioelectron., 2005, 20, 1856 - 1859. 
7 Tront JM, Fortner JD, Pl?tze M, Hughes JB, Puzrin AM. Biosens Bioelectron., 2008, 24 (4), 586-90.

8 Di Lorenzo M, Curtis TP, Head IM, Scott K. Water Res., 2009, 43 (13), 3145-54.

9 Liu Z, Liu J, Zhang S, Xing XH, Su Z. Bioresour Technol., 2011, 102 (22), 10221-9.

10 Leland C. Clark Jr. and Champ. Annals of the New York Academy of Sciences, 1962, 102, 29-45.

11 Sejin Park, Hankil Boo, Taek Dong Chung. Analytica Chimica Acta, 2006, 556, 46-57.

12 Jing-Fang Huang. Electroanalysis, 2008, 20, 2229.

13 Sejin Park, Taek Dong Chung, and Hee Chan Kim. Anal. Chem., 2003, 75 (13), 3046-3049.

14 Sabahudin Hrapovic, Yali Liu, Keith B. Male, and John H. T. Luong. Anal. Chem., 2004, 76 (4), 1083-1088.

15 Liang Su, Wenzhao Jia, Lichun Zhang, Cynthia Beacham, Heng Zhang, and Yu Lei. Journal of Physical Chemistry C., 2010, 114 (42), 18121-18125.

16 Sangeun Cho, Chan Kang. Electroanalysis, 2007, 19 (22), 23152320.

17 Yue Xia, Wei Huang, Jufang Zheng, Zhenjiang Niu, and Zelin Li. Biosens Bioelectron, 2011, 26 (8), 3555-61.

18 Li-Min Lu, Li Zhang, Feng-Li Qu, Hai-Xia Lu, Xiao-Bing Zhang, Zai-Sheng Wu, Shuang-Yan Huan, Qiu-An Wang, Guo-Li Shen, Ru-Qin Yu. Biosens Bioelectron, 2009, 25 (1), 218-223.

19 Annamalai Senthil Kumar, Pei-Yen Chen, Shu-Hua Chien, Jyh-Myng Zen. Electroanalysis, 2005, 17 (3), 210-222.

20 Jingpeng Wang, Dan F. Thomas, and Aicheng Chen. Anal. Chem., 2008, 80 (4), 997-1004.

21 Li-Hua Li, Wei-De Zhang, Jian-Shan Ye. Electroanalysis, 2008, 20 (20), 2212-2216.

22 Levent zcan, Yücel ahin, Hayrettin Türk. Biosens Bioelectron, 2008, 24 (4), 512-517.

23 Craig E. Banks and Richard G. Compton. Analyst, 2006, 131, 15-21.

24 Hyunju Lee, Sang Won Yoon, Eun Joo Kim, and Jeunghee Park. Nano Lett., 2007, 7 (3), 778-784.

25 Daibing Luo, Liangzhuan Wu and Jinfang Zhi. ACS Nano, 2009, 3 (8), 2121-2128.

26 Keith B Male, Sabahudin Hrapovic, Yali Liu, Dashan Wang, and John H.T Luong. Analytica Chimica Acta, 2004, 516 (1-2), 35-41.

27 Hui-Xia Wu, Wei-Man Cao, Yan Li, Gang Liu, Ying Wen, Hai-Feng Yang, and Shi-Ping Yang. Electrochimica Acta, 2010, 55 (11), 3734-3740.

28 Yuchan Zhanga, Liang Su, Dan Manuzzi, Honorio Valdés Espinosa de los Monteros, Wenzhao Jia, Danqun Huo, Changjun Hou, and Yu Lei. Biosens Bioelectron, 2012, 31 (1), 426-432.

29 a) Yuxin Zhao, Ying Zhang, Yanpeng Li and Zifeng Yan. New J. Chem., 2012, 36, 1161-1169. b) Yuxin Zhao, Ying Zhang, Yanpeng $\mathrm{Li}$ and Zifeng Yan. New J. Chem., 2012, 36, 130-138.

30 D. Pletcher, J. Appl. Electrochem., 1984, 14, 403.

31 Yuxin Zhao, Juan Wang, Ying Zhang, Yanpeng Li and Zifeng Yan. New J. Chem., 2012, 36, 1255-1264.

32 Keith B. Male, Sabahudin Hrapovic, Yali Liu, Dashan Wang, and John H.T. Luong. Analytica Chimica Acta, 2004, 516, 35-41.

33 Xinhuang Kang, Zhibin Mai, Xiaoyong Zou, Peixiang Cai, and Jinyuan Mo. Analytical Biochemistry, 2007, 363, 143-150.

34 Hui-Xia Wu, Wei-Man Cao, Yan Li, Gang Liu, Ying Wen, Hai-Feng Yang, and Shi-Ping Yang. Electrochimica Acta, 2010, 55, 37343740 .

35 Jing Luo, Sisi Jiang, Hongyan Zhang, Jinqiang Jiang, Xiaoya Liu. Analytica Chimica Acta, 2012, 709, 47-53.

36 C. Casiraghi, A. C. Ferrari, and J. Robertson. PHYSICAL REVIEW B, 2005, 72, 085401.

37 C. H. Lau, R. Cervini, S. R. Clarke, M. G. Markovic, J. G. Matisons, S. C. Hawkins, C. P. Huynh and G. P. Simon. J. Nanopart. Res., $2008, \mathbf{1 0}, 77-88$

38 Ruimin Ding, Jian Jiang, FeiWu, MinGong, Jianhui Zhu and Xintang Huang. Nanotechnology, 2011, 22, 375303.

39 Yang Liu, Zhen Liu, Ning Lu, Elisabeth Preiss, Selcuk Poyraz, Moon J. Kim and Xinyu Zhang. Chem. Commun ., 2012, 48, 2 621-2623.
40 Ting-Kai Huang, Kuan-Wen Lin, Sze-Ping Tung, Ta-Ming Cheng, IChun Chang, You-Zung Hsieh, Chi-Young Lee, Hsin-Tien Chiu. Journal of Electroanalytical Chemistry, 2009, 636, 123-127.

41 Valber A. Pedrosa, Rigved Epur, Jessica Benton, Ruel A. Overfelt, Aleksandr L. Simonian. Sensors and Actuators B, 2009, 140, 92-97.

42 Li X, Zhu Q Y, Tong S F, Wang W and Song W B. Sensors Actuators B, 2009, 136, 444.

43 Xuemei Zhou, Huagui Nie, Zhen Yao, Youqing Dong, Zhi Yang, Shaoming Huang. Sensors and Actuators B, 2012, 168, 1-7.

44 Zhenjing Zhuang, Xiaodong Su, Hongyan Yuan, Qun Sun, Dan Xiao and Martin M. F. Choi. Analyst, 2008, 133, 126-132.

45 W. Wang, L.L. Zhang, S.F. Tong, X. Li, W.B. Song. Biosensors \& Bioelectronics, 2009, 25, 708-714.

46 K.M.E. Khatib, R.M.A. Hameed, Biosensors \& Bioelectronics, 2011, 26, 3542-3548.

47 C.L. Li, Y. Su, S.W. Zhang, X.Y. Lv, H.L. Xia, Y.J. Wang, Biosensors \& Bioelectronics, 2010, 26, 903-907.

48 L.C. Jiang, W.D. Zhang. Biosensors \& Bioelectronics, 2010, 25, 1402-1407. 